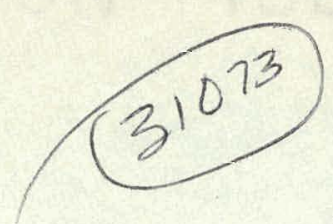

IS-T-562

\title{
MAGNETIC FIELD CONTROL IN A BETA-RAY SPECTROMETER
}

M.S. Thes is Submitted to lowa State University, November, 1972

\author{
J. K. Halbig
}

\begin{abstract}
Ames Laboratory, USAEC
lowa State University

Ames, lowa 50010
\end{abstract}

Datc of Manuscripl: November, 1972

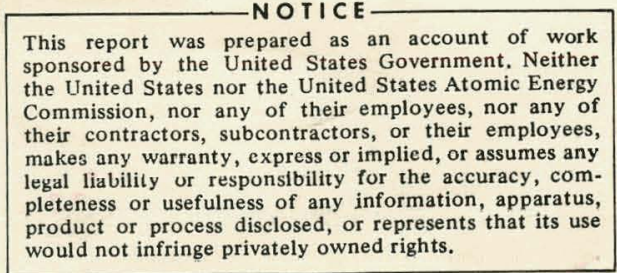

PREPARED FOR THE U.S. ATOMIC ENERGY COMMISSION DIVISION OF RESEARCH UNDER CONTRACT NO. W-7405-eng-82 


\section{DISCLAIMER}

This report was prepared as an account of work sponsored by an agency of the United States Government. Neither the United States Government nor any agency Thereof, nor any of their employees, makes any warranty, express or implied, or assumes any legal liability or responsibility for the accuracy, completeness, or usefulness of any information, apparatus, product, or process disclosed, or represents that its use would not infringe privately owned rights. Reference herein to any specific commercial product, process, or service by trade name, trademark, manufacturer, or otherwise does not necessarily constitute or imply its endorsement, recommendation, or favoring by the United States Government or any agency thereof. The views and opinions of authors expressed herein do not necessarily state or reflect those of the United States Government or any agency thereof. 


\section{DISCLAIMER}

Portions of this document may be illegible in electronic image products. Images are produced from the best available original document. 


This report was prepared as an account of work
sponsored by the United States Government. Neither
the United States nor the United States Atomic
Energy Commission, nor any of their employees, nor
any of their contractors, subcontractors, or their
employees, makes any warranty, express or implied,
or assumes any legal liability or responsibility for the
accuracy, comple teness or usefulness of any
information, apparatus, product or process disclosed,
or represents that its use would not infringe privately
owned rights.

Available from: National Technical Information Service Department A

Springfield, VA 22151

Price: Microfiche $\$ 0.95$ 
iii

$15-T-562$

Magnetic field control in a beta-ray spectrometer

by

James Kent. Halbig

A Thesis submitted to the

Graduate Faculty in partial Fulfillment of

The Requirements for the Degree of

MASTER OF SCIENCE

Major: Electrical Engineering.

Approved :

In Charge of major tor

For $\frac{\text { She }}{3 a} \frac{3}{\text { jor }}$ Department

Chad the Shodenck

For the Graduate College

Iowa State University Ames. Iowa

1972 
TABLE OF CONTENTS

page

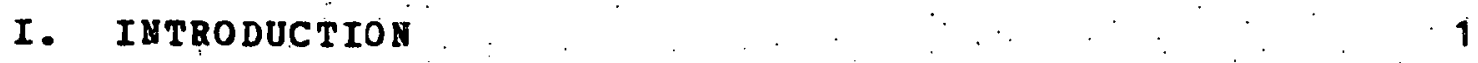

II. ANALYSIS 10

A. Spectromagnetic supply - spectrometer subsystem

B. Alpha scientific Supply-solenoid subsystem

c. Magnetometer - Probe Subsystem

D. Non-constant Permeabiliti Effects

III. DESIGH

A. Intuitive Discussion $\quad 24$

B. General Response Analysis $\quad 25$

C. Stability 31

IV. EVALUATION $\quad 32$

A. System 1

B. System 2

c. Onpredicted Instability 34

v. LITEBATURE CITED $\quad 36$

VI. ACKHOHLEDGEENTS 37

VII APPEHDIX: CIRCUIT DIAGRAE $\quad 38$ 
Page

Fiqure 1. The beta-ray spectrometer

Pigure 2. Block diagram of original iagnetic field control spstem

Figure 3. Setup used to determine response of power supply - coil subsystems

Figure 4. Simplified model of the spectrometer used in the analysis of the response of the Spectromagnetic supply - spectrometer subsystem

Fiqure 5. Response of the spectromagnetic supply spectrometer subsystem to a step input

Fiqure 6. Response of Alpha Scientific Supply Solenoid subsystem

Fiqure 7. Setup used to determine response of Magnetoneter - Probe subsystem

Figure 8. Frequency response of uagnetometer - probe subsystem

Figure 9. Non-constant permeability effects on error voltage necessary to null field at the center of the solenoid

Fiqure 10. Non-inear response of spectromagnetic supply - spectrometer subsystem

Fiqure 11. Siqnal flor diagram of system 1

Fiqure 12. Signal floy diagram of system 2

Piqure 13. Root-locus diagram of system 2

Piquie 14. Root-locus diagrams of systems 1 and 2

Piqure A1: Schematic diagram of field stabilizer 


\section{LIST OF TABLES}

Page

Table 1. Comparison of stabilization times 


\section{INTEODOCTION}

In the field of auclear spectroscopy the magnetic betaray spectrometer has proven to be a valuable research tool. There are many designs for magnetic beta-ray speztrometers, all of which utilize the principle that the paths of charged particles are bent in a magnetic field. The beta-ray spectrometer used in this work has been described in detail by Eitter and Talbert (1).

The essential operation of the spectrometer can be described briefly ith the aid of figure 1. A radioactive source wich enits beta particles (electrons) is located at the source position s. Immediately in front of the source is a slot wich defines the electron beam. a detector is located at position D. The source, source slits and the detector are all located on the same characteristic rajius $\rho$. An electron moving transversely in a uniform magnetic field follows a circular path of radius, f which is given by

$$
r=P /(q B)
$$

where $\underline{P}$ is the electron!s momentum, and $g$ is its charge. The strength of the magnetic field is representel by Hence. for a particular field strength only electrons of a specific momentum will be seen by the detector. In the $\pi \sqrt{2}$ maqnetic spectrometer, tha magnetic field has rotational symetry and the magnetic field varies along the radius 


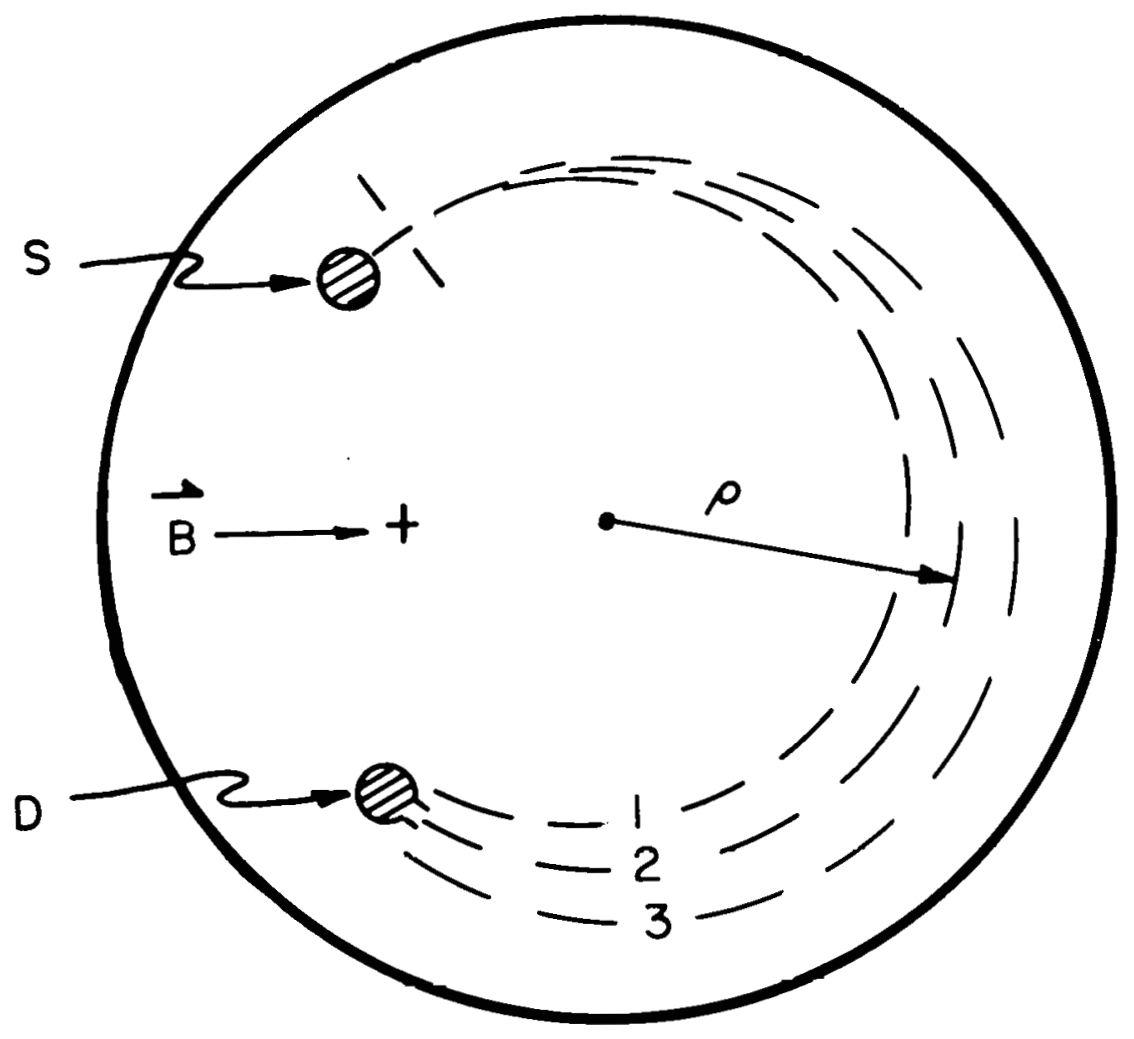

Figure 1. The beta-ray spectrometer 
approximately as

$$
\text { B } \propto\left(\frac{1}{r}\right)^{\frac{1}{2}}
$$

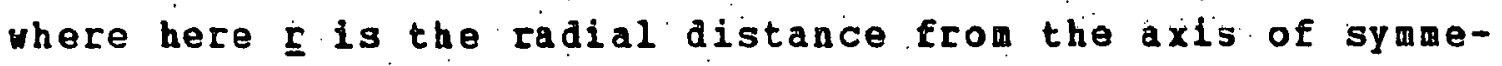
try. These characteristics spatially focus the electron bean (2). In principle, then, one can use this instrument to investigate particles of a particular momentua by proper choice of the magnetic field strength. In reality, hovever, there are aberrations inherent in the design of the spectrometer which, by adjustment of the field shape, can be inimized but not eliminated. and source uidh effects and source thickness effects wich cause a "defocusing" of the electrons. Thus in fiqure 1, electrons with paths 1 and 3 see different arerage fields than the electrons with path 2 which are seen by the detector. As the defocusing effects of the electron beandecrease, the resoluing power of the spectrometer increases. The high-resolution, magnetic beta-ray spectrometer is unequaled in its potential ability to resolve structure in a lor-enerqy beta spectrum, and to measure higher energy (3-8 MeV) electron spectra with low distortion. To Eully realize this potential it is necessary to be able to set, maintain and reproduce the magnetic field in the beta spectrometer. Noise and short term drifts in the system. which supplies the current to the coils of the spectrometer can reduce the resolving poter of the spectrometsr. In addition, any drift in the system can degrade both the accuracy 
of calibration and the reproducibility of the instrument.

Since the advent of studies of short-lived nuclei with half-lives of the order of seconds it has become necessary to require that the field control syster also have a rapid settling time, i.e.. the time necessary for the magnetic field to stabilize to within liaits set about the desired maqnetic field value. otherwise significant amounts of source activity can be lost whie the field is stabilizing to within the field limits at wich data ls to be taken. Furthermore, the duty factor, i.e., the percent of the total run time that activity is being collected and/or data are being accumulated, is appreciably reduced.

Por iron-free spectrometers, it is sufficient to have a good quality. programable constant-current supply. It is necessary then on ly to provide the proper programing voltage to obtain the desired field, since the field is directly proportional to the current uhich is directly proportional to the programing voltage. For spectrometers vithiron pole faces, the situation is not so simple. The hystereais: of the iron does not allow a unique field value to result for:a qiven current supplied to the magnet coils, and the field is not a linear function of current since the relative perteability of the iron is a function of the magnetic field.

For iron spectroweters, a peaking-strip technique has been used as a reliable method to control the magnetic field 
$(1,3,4)$. This technique requires that an iron-free solenoid be placed inside the magnetic spectrometer vith the field of the solenold aligned antiparallel to the field of the spectrometer. Current is supplied to the solenoid by a programmable, constant current source. The field inside the solenoid is directly proportional to the curient from the current source and hence, to the programing roltage. after the field has been set in the solenoid, the current in the spectrometer magnet is changed until its field exactly cancels the field due to the solenoid at the center of the solenoid: The current in the spectrometer is changed by a voltage proportional to any non-nuli field at the center of the solenoid. This voltage is fed back to the controling electronics.

Pield control using a direct field measuring device in place of the solenoid is possible; hovever, direzt measurement of magnetic field strengths from 10 to 1000 gauss on a single range to within several milligauss is difficult. With rotating-coil magnetometers, such accuracy and stability is on the edge of practicability l and the mechanical nature of the probe reguires frequent servicing and is a continual source of headaches. Hall-effect devices are plagued ith

ILush, M. Jo, President, Rauson-Lush Instrument Ca, Inc...Acton, Massachusetts. Private Commurication. 1972: 
two problemsi. The first is that the temperature dependence of the Hall probe is nominally 50 parts per nillion per centigrade degree, and that the temperature dependence of the associated electronics is nominally 100 parts per million per centigrade degree. The second is a signal-to-noise ratio problem wen trying to resolve 2.5 milligauss on the 1 kilogauss scale. It becomes apparent then that the solenoid coil, combined with a null probe, is the most satisfactory means of controlling the field in a high-resolution beta-ray spectrometer.

The original design of the field control system used for the TRISTAN beta-ray spectrometer utilized the peaking-strip technique. A block diagram of this design, uhich is presented by Eitter and Talbert in the detailed description of the beta-ray spectrometer (1). is shown in figure 2. The proqramable Digital Eield selector (묘포) and the Alpha scientific pover supply have replaced older equipment described by Eitter. Por completeness it is necessary to add only that the RDFS in conjunctioü with the Fiuke voltage Supply $383 \mathrm{~B} / \mathrm{A}$ provides the voltage wich programs the Alpha scientific power supply. The programing voltage changes from one value to another through a series of 40 microvolt steps, each step

Chapman. Dick, Chief Engineer; F. Bell, Inc., Columbus, ohio. Private Communication. 1972. 


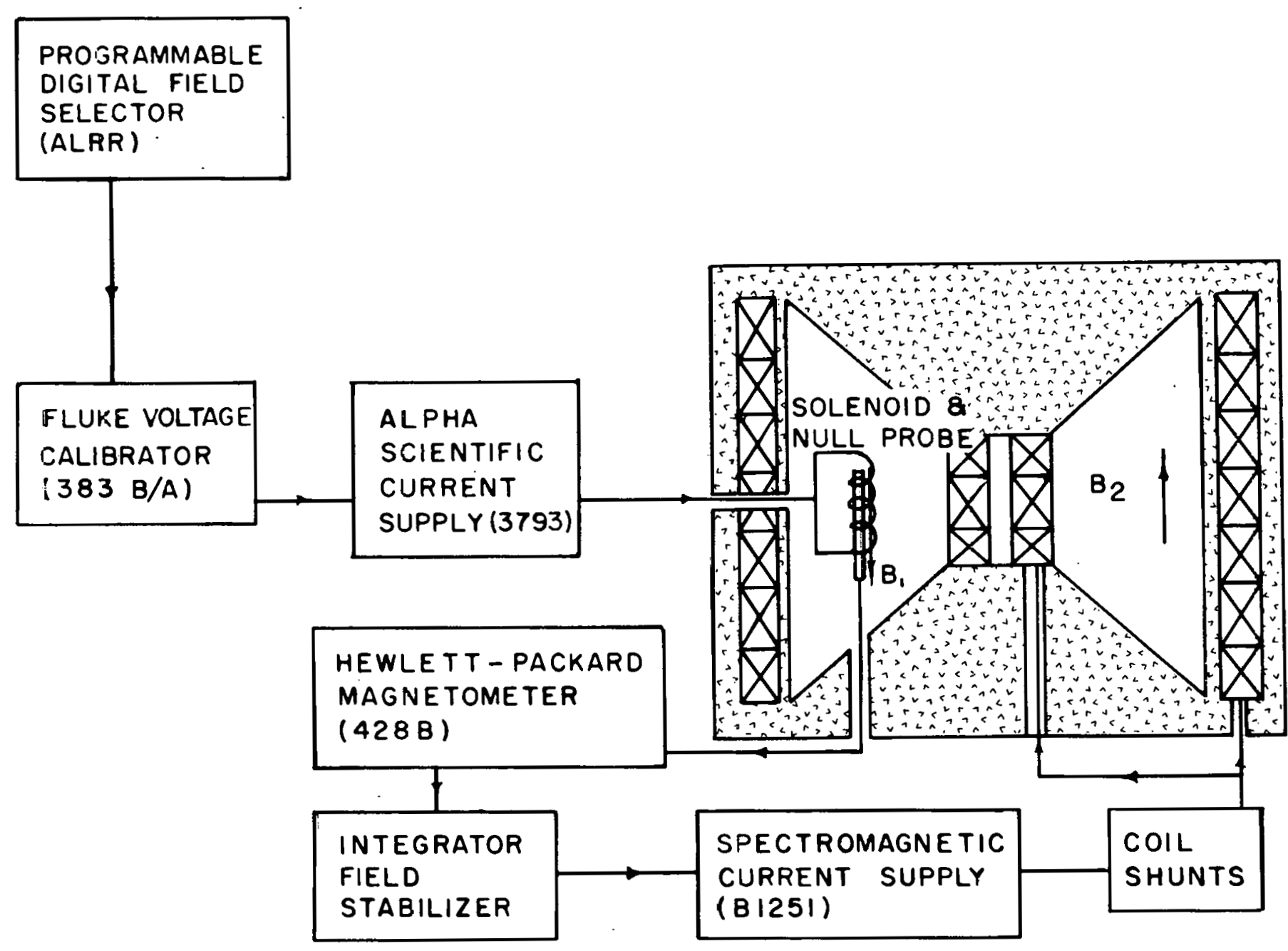


is equivalent to 2.3 milligauss. The stepping rate is nominally 500 steps per second for an increase in field and 1500 steps per second for a decrease in field.

The original specifications set down for this system required field reproducibility and stability of 10 milligauss. Because of the ambiguity of the manner in which the tests of system performance vere carried out by Eitter and Talbert, the performance of the system was re-evaluated, this time using the pDEs and the Alpha scientific poyer supply. The results revealed three highli undesirable characteristics:

1) Drifts exceeding 95 milligauss vere observed.

2) The stabilization time, i.e., the time after completion of current stepping required for the field to restabilize vithin 10 milligauss of the desired field, was found to be 4.8 seconas for a 0.115 -gauss step, 8.0 seconds for a 0.23 -gauss step and 12.4 seconds for a 2.3 -gauss step:

3) For fiela steps larger than 18 gauss the field error became so. large that the error signal from the magnetometer probe changed polarity, resulting in system instability:

The third characteristic is extremely harmful when the field control program recycles the field from its maximum value to 
its minimum value, a step normally much greater than 18 qauss.

The design problem of this work was to develop a magnetic field control system for the TBISTAN beta-ray spectrometer which would meet the following requirements for fields from 10 to 1000 gauss.

1) Rield stability and reproducibility to within 10 milligauss.

2) Control system stability for any size field step.

3) Settling time of less than 2 seconds for a 0.23-qauss field step. 
II. ANALYSIS

The response functions of the various components used in the control system were experimentaliy deterined. The procedure followed for the porer supply-coil subsystems ras to use a Sanborn Model 297 chart recorder to monitor the response of the subsystems to a step input. A diagram of this setup is shown in figure 3. These data vere then fit by an assumed function using. a program (5) which adjusted the parameters of the assumed function to obtain a minimum leastsquares fit. The response function of the Herlett-Packard magnetometer and its probe was determined from an experimentally deterained frequency response:

A. Spectromagnetic supply - spectrometer subsystem Basically, the spectrometer consists of ten coils in series. Each coil is shunted with a variable resistor which allows adjustment of the relative currents through the individual coils and hence, of the field shape inside the spectrometer. A simplified model was used in the analysis of the spectrometer. This model, shown in figure 4, uses one coil and one shunt resistor in place of the ten LE parallel circuits in series. The resistance of the spectrometer coils. $\underline{R}_{L}$. is 31.5 ohws. The shunt resistance, $\underline{R}_{S}$, is 288 ohms. The capacitance $\subseteq$ is internal to the pover supply and 


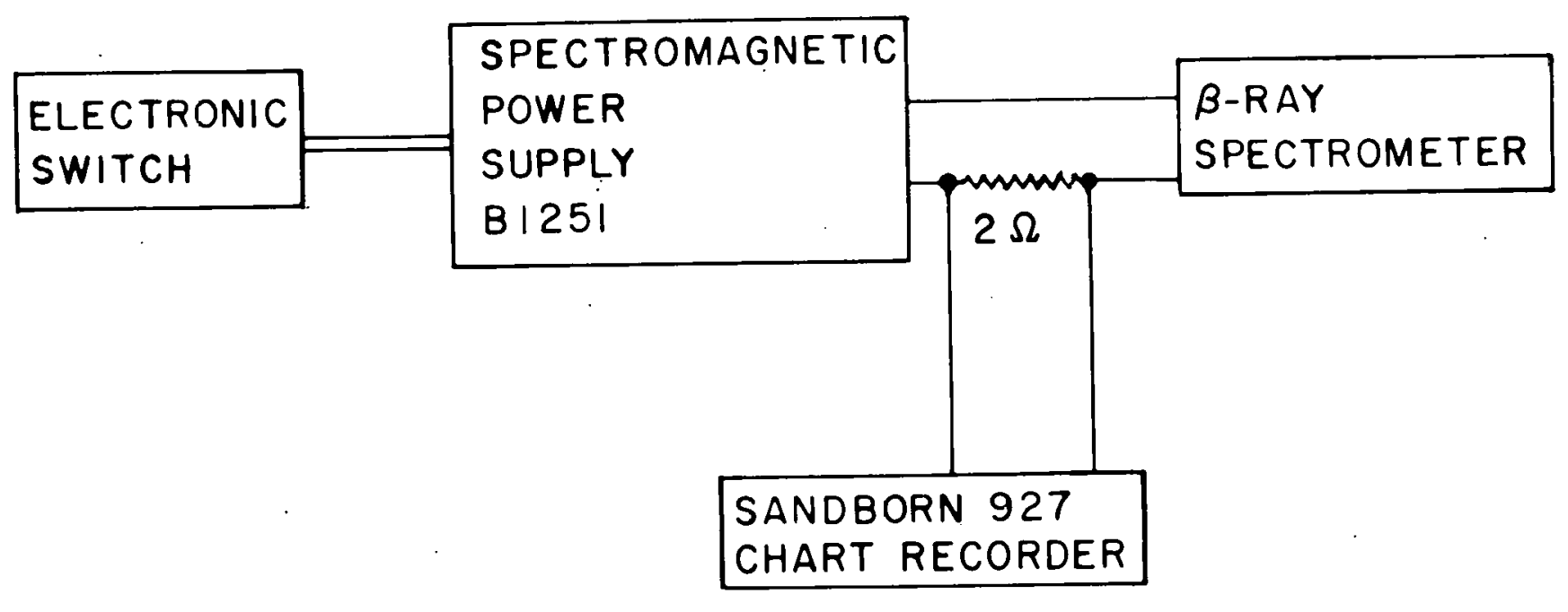

Figure 3. Setup used to determine response of power supply - coil subsystems 


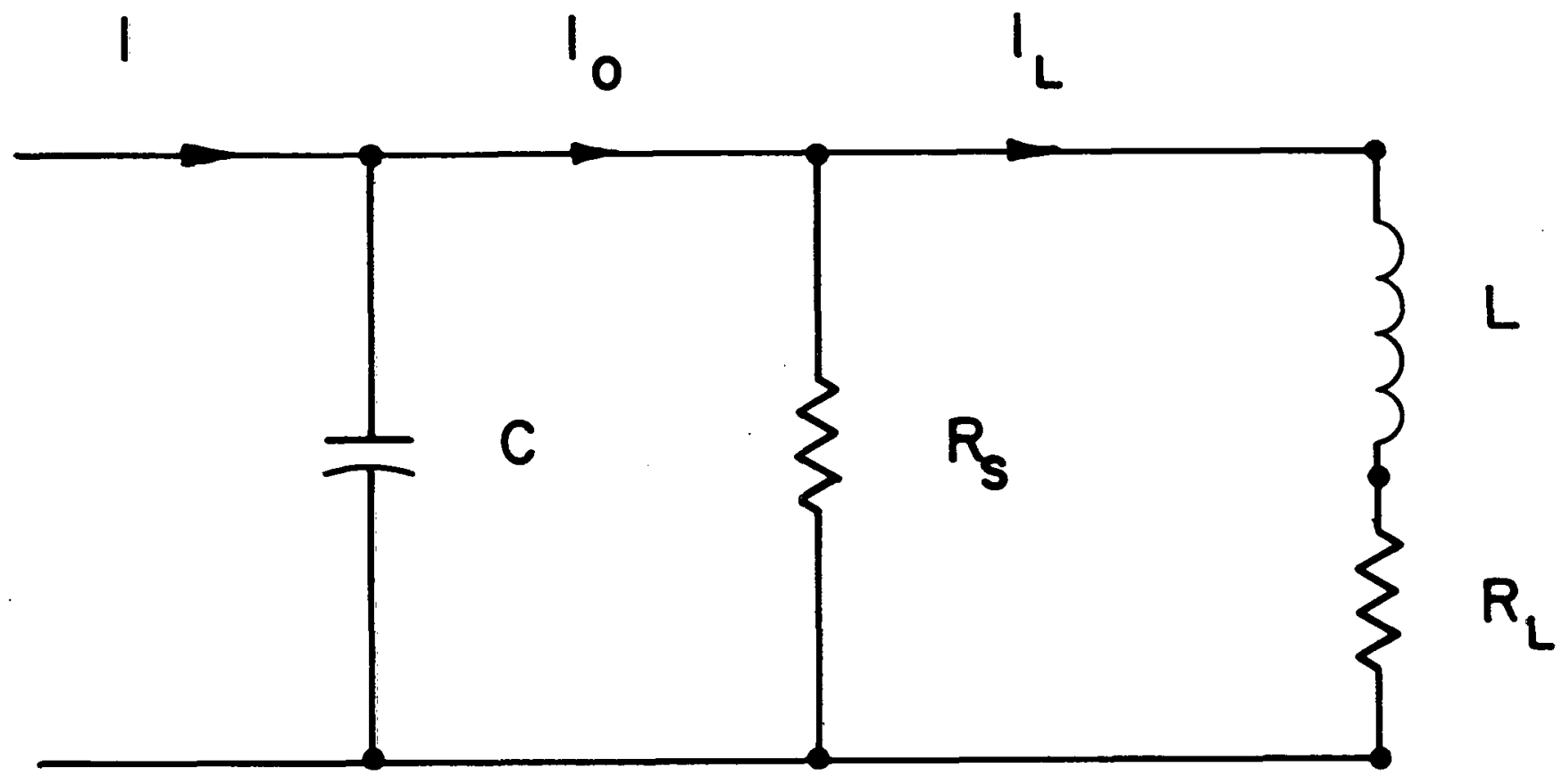

$\vec{N}$

Figure 4. Simplified model of the spectrometer used in the analysis of the response of the spectromagnetic Supply - spectrometer subsystem 
has a value of 120 microfarads. The value of the inductance of the spectrometer coils, L, is approximately 19 henrys. As a first approximation then, one may assume that the response of this subsysten will be dominated by the response of the spectrometer coils. Analysis of the systen in figure 4 reveals that

$$
I(s)=I_{0}(s) \frac{w_{n}^{2}(1+a s)}{s^{2}+2 \delta w_{n}+w_{n}^{2}}
$$

where

$$
a=\frac{L}{R_{L}+R_{S}} \quad 2 \delta \omega_{n}=\frac{R_{L}}{L}+\frac{1}{R_{S} C}
$$

and

$$
\omega_{n}^{2}=\frac{R_{L}+R_{S}}{L C R_{S}}
$$

The discrete points in figure 5 represent data indicating the response of this subsystem to a step input. The error bars represent the uncertainty in reading the data from the strip chart recorder. These points were fit using the equation

$$
R(T)=N\left[1+\frac{D}{A} \exp \left(-x w_{n} T\right) \sin \left(\omega_{n} A T+\Phi\right)\right]
$$

where

$$
\begin{aligned}
& A=\sqrt{1-x_{1}^{2}} \\
& w_{n}=\frac{\pi}{A} \frac{1}{x_{3}} \\
& D=1-2\left(x_{1} x_{4} w_{n}\right)+x_{4}{ }^{2} w_{n}{ }^{2}
\end{aligned}
$$




$$
\begin{gathered}
\Phi=\operatorname{ARCTAN}\left[\frac{x_{4} w_{n} A}{1-x_{1} x_{4} w_{n}}+\operatorname{ARCOS}\left(x_{1}\right)\right] \\
\quad T=T^{1}+x_{2}
\end{gathered}
$$

which is the inverse transform of the transfer function of the spectromagnetic supply - spectrometer subsystem where $\underline{T}^{\prime}$ is the elapsed time measured from the time the step input function was applied. The parameter $\underline{x}_{2}$ was introduced to allow for error in designating the time at which $\underline{\underline{T}}=0$ on the strip chart. A small error in $\underline{T}^{\prime}$ greatly affects the character of the fit function, and hence, probibits the true determination of the other parameters uhich are linked to the control system response. The time at which the putput reaches its first relative maximu value is the physical interpretation of $\underline{x}_{3}$. The coefficient $\underline{N}$ is a normalization coefficient. The parameter $\underline{x}_{1}$ corresponds to $\delta$ in the transfer function, and $\underline{x}_{4}$ corresponds to a... The parameters vhlch gave the fit represented by the solid line in figure 5 give

$$
\begin{aligned}
& \dot{a}=0.282 \\
& \delta=0.766 \\
& \omega_{n}=4.548
\end{aligned}
$$

The value of $x_{2}$ was 0.0115 , yhich is much less than the uncertaintity in determining $\underline{T}^{\prime}=0$ from the strip chart. 


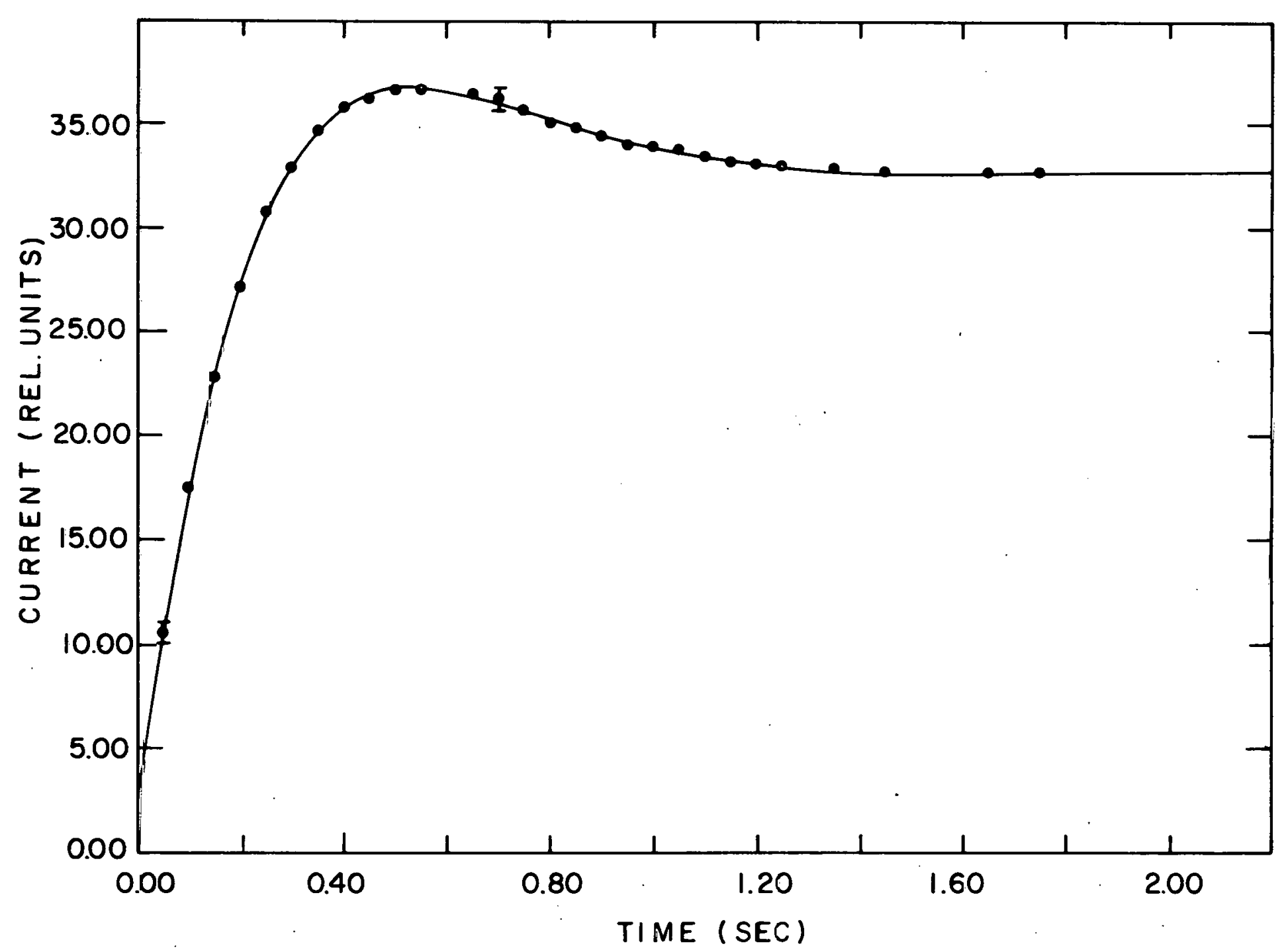

Figure 5. Response of Spectromagnetic Supply - Spectrometer subsystea to a step input 
The quality of the fit shown in figure 5 allows one to conclude that the model shown in figure 3 accurately describes the subsystem and that the parameters of the transfer function of this subsysten are those given above.

B. Alpha scientific supply - Solenoid subsystea

The experimental response of the Alpha scientific supply - Solenold subspted represented by discrete points in figure 6 was fit using the inverse lapiace transfori of the transfer function.

$$
T P=M /(S+E)
$$

The solid line shous the fit achiered using $E=9.4582$; is a normalization constant.

\section{Magnetometer - Probe Subsystem}

The frequency response of this subsystem was determined by rapping a coil of wire around the agnetometer probe and applying a signal of known frequency and anplitude to the coil wile at the same time monitoring the output of the magnetometer. A block diagram of this setup is shown in Eigure 7 .

The experinental response for this subsyster is shown by the discrete points in figure 8. The fit to these points is that of a syster with a single pole on the real axis at -605 radians per second. This is obviously not a good fit beyond 


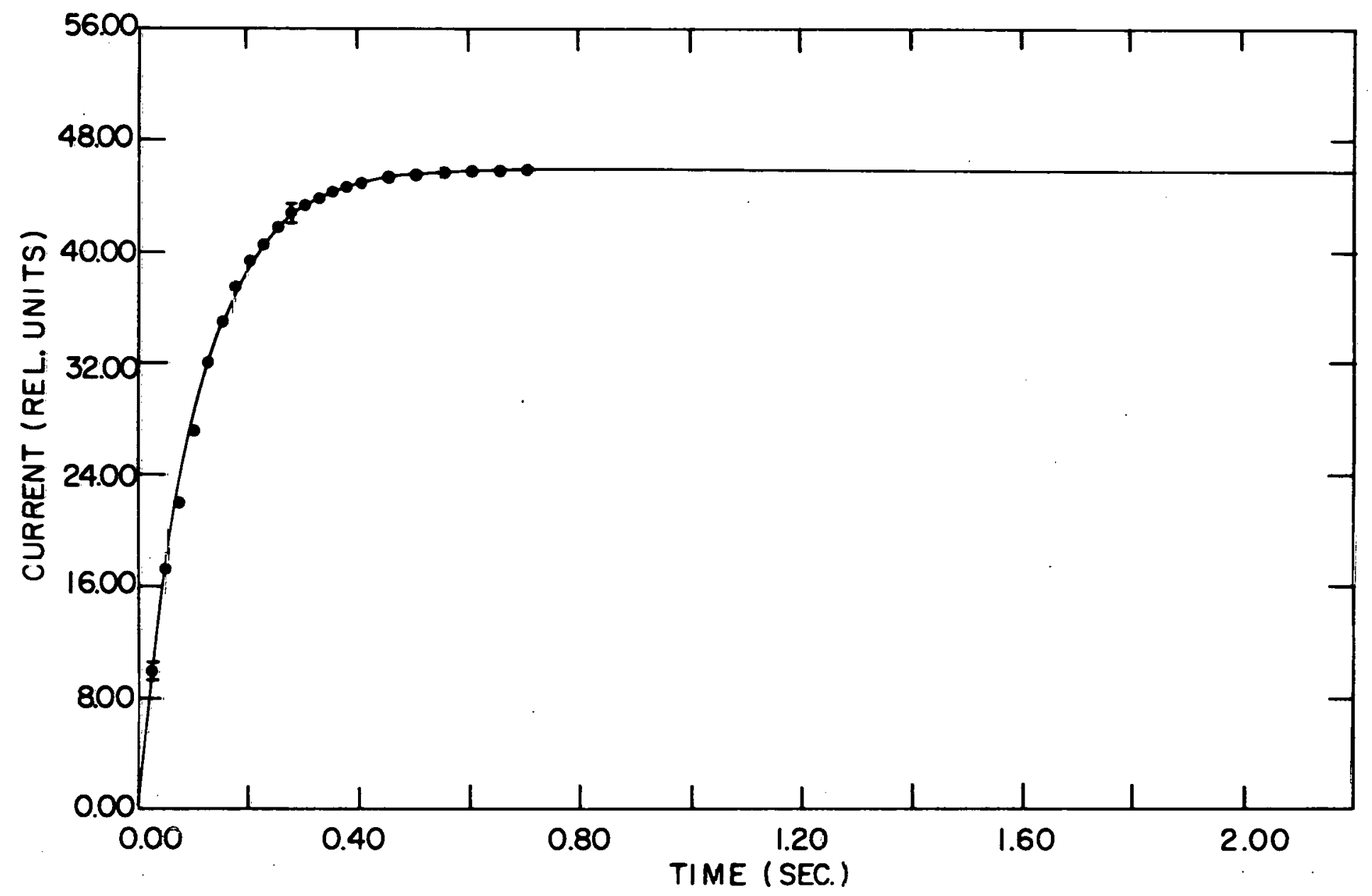




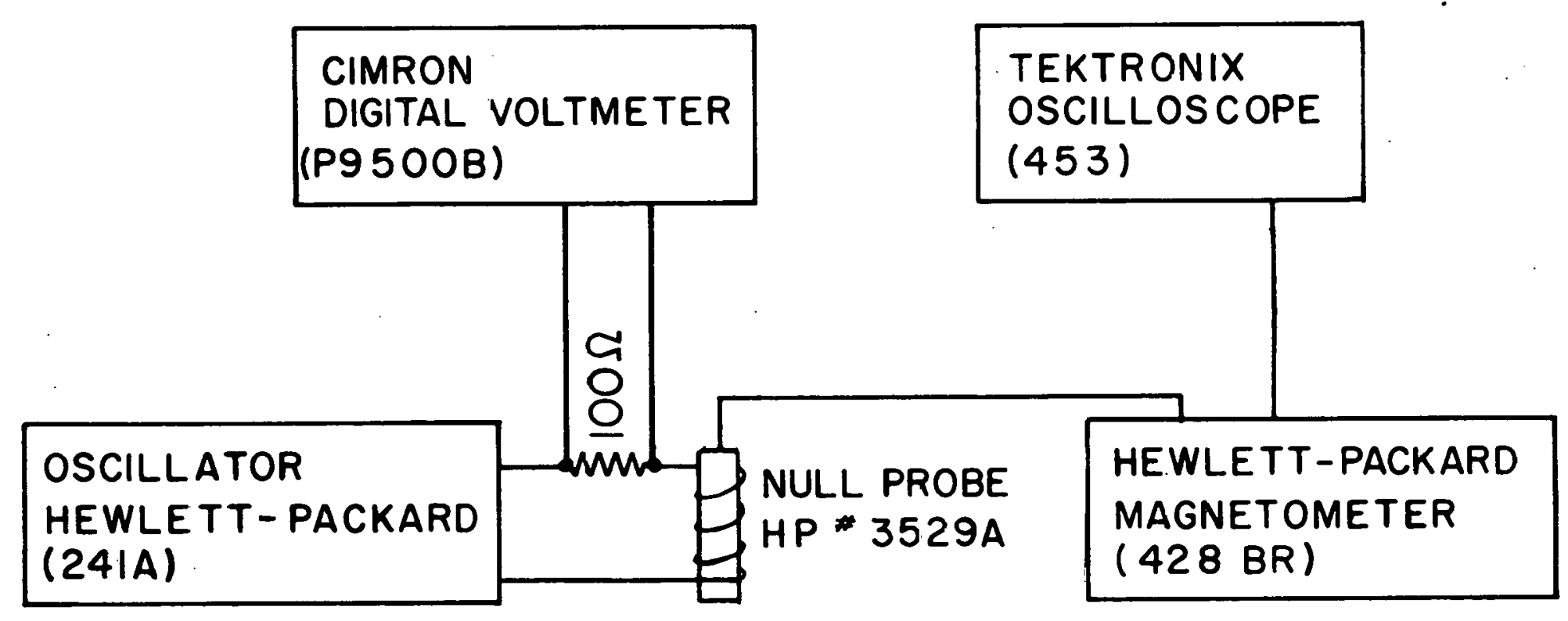

Pigure 7. Setup used to determine response of lagnetometer - Probe subspstem 


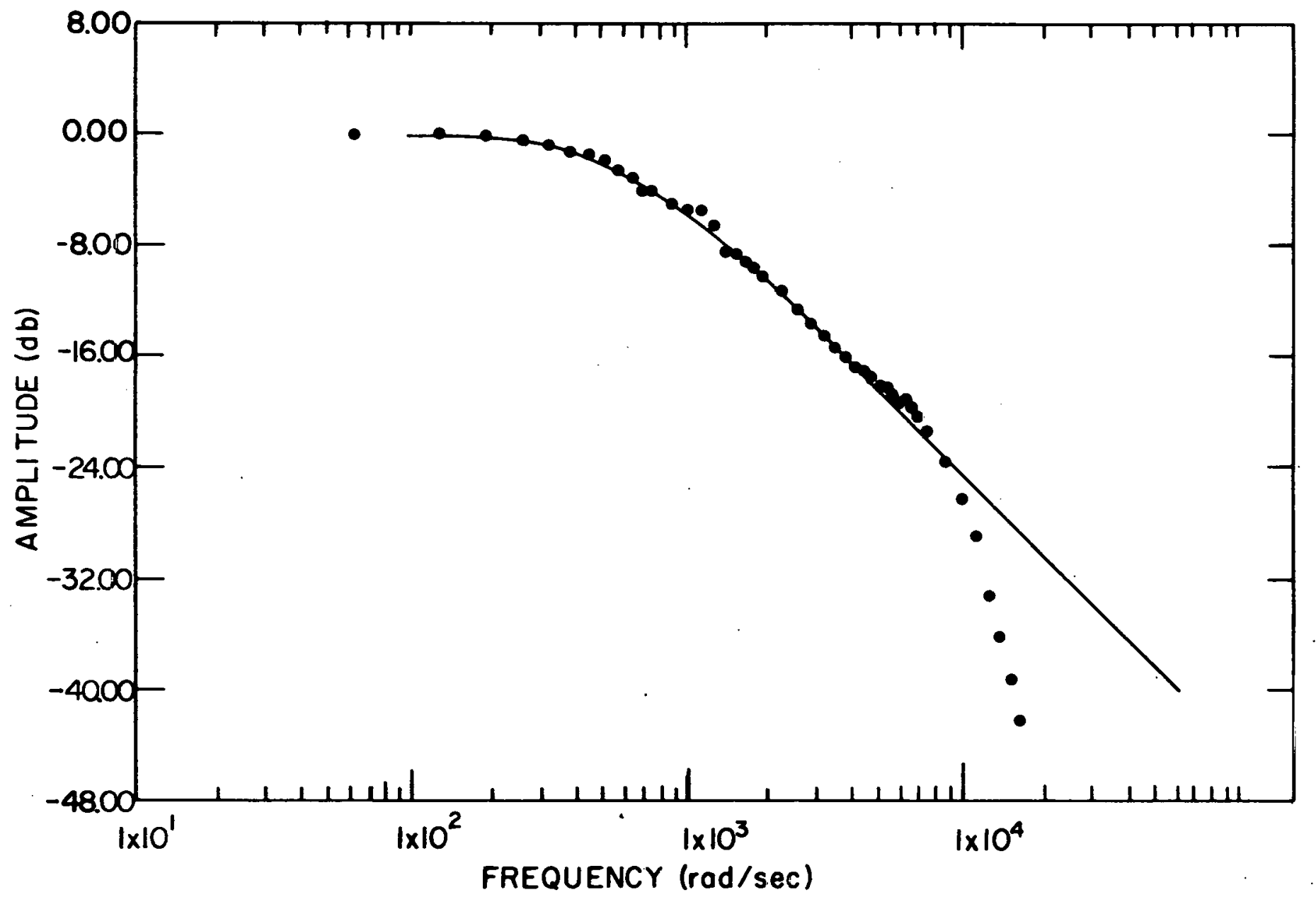

$\overrightarrow{0}$

Figure 8. Prequency response of lagnetoneter - Probe subsystem 
4000 radians per second: however, since the other system components have auch narrower frequency responses. such a model is adequate here to describe the Magnetometer - Probe subsystem; therefore, the transfer function can be specified as

$$
T F=J /(S+H)
$$

where $\underline{J}$ is a norwalization constant and $\underline{H}=605$.

$$
\text { D. Mon-constant Permeability Effects }
$$

The voltage necessary to offset the non-constant permeability effects in the spectrometer as a function of current in the spectrometer coils is shown in figure 9. These data represent the integrated error voltage which must be supplied, in addition to the programming voltage for a given current in the solenoid, to the input of the spertromagnetic power supply to attain a null field at the center of the solenoid. The voltages vere measured ith a cimron p9500B diqital voltmeter.

Before these data were taken. the spectrometer uas completely demagnetized by driving the spectrometer field around successively smaller hysteresis loops until the residual maqnetism of the iron in the spectrometer was reduced to near zero. The demagnetization was required to eifimate hysteresis effects.

To complete the discussion of the analysis it should be pointed out that the tro subsystems $A$ and $B$ above are only 


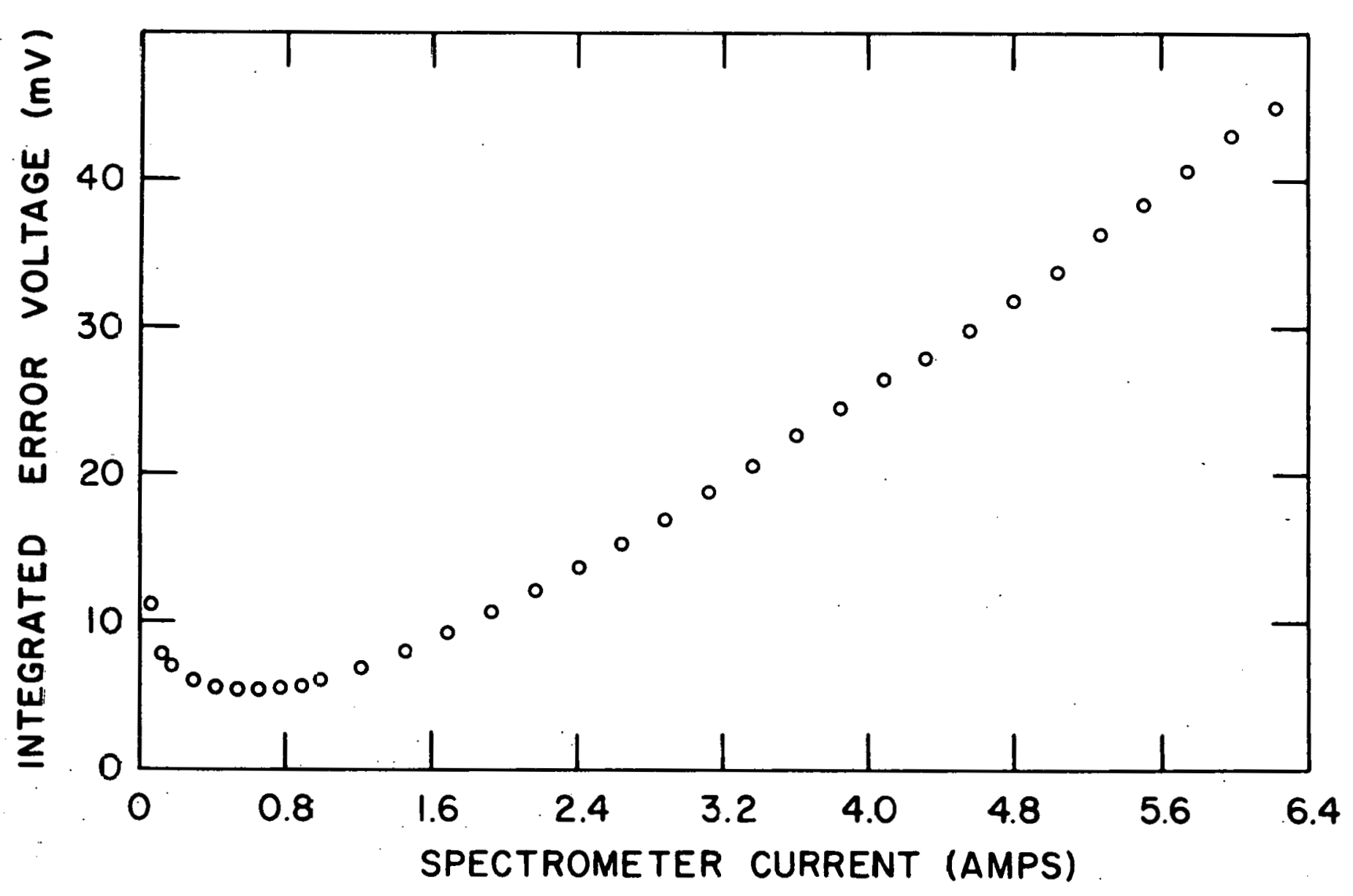

Figure 9. Non-constant permeability effects on error voltage necessary to null field at the center of the solenoid 
piece-wise linear inasmuch as they are electronically controlled only when the output voltage change required to maintain or achieve the programmed current change is less than a qiven amount. If the required voltage change exceeds this given amount, the powerstats are mechanically turned up or down and the systems can no longer be treated as linear systems with the transfer functions given above. Figure 10 shows the response of the spectromagnetic supply - spectrometer subsystem to a step input which was sufficiently large to cause the powerstat to slew. At point a on the curve the step input was remored. The effect of the limited linear ranges of the supplies was found to manifest itseif about every 6 gauss in the region from 25 gauss to 125 gauss. The problen will not be encountered frequently in measurements of internal conversion electron peaks wich typically require steps of 0.025 gauss over a region of 1 gauss. Por measurements of continous beta-ray spectra, howerer, the problem. will be encountered more often. Although there are instances where these subsystems become non-linear, it is beyond the scope of this work to do a non-linear analysis of the total system, and it is sufficient to assure that the non-linearity will never cause a condition were the field will not stabilize. 


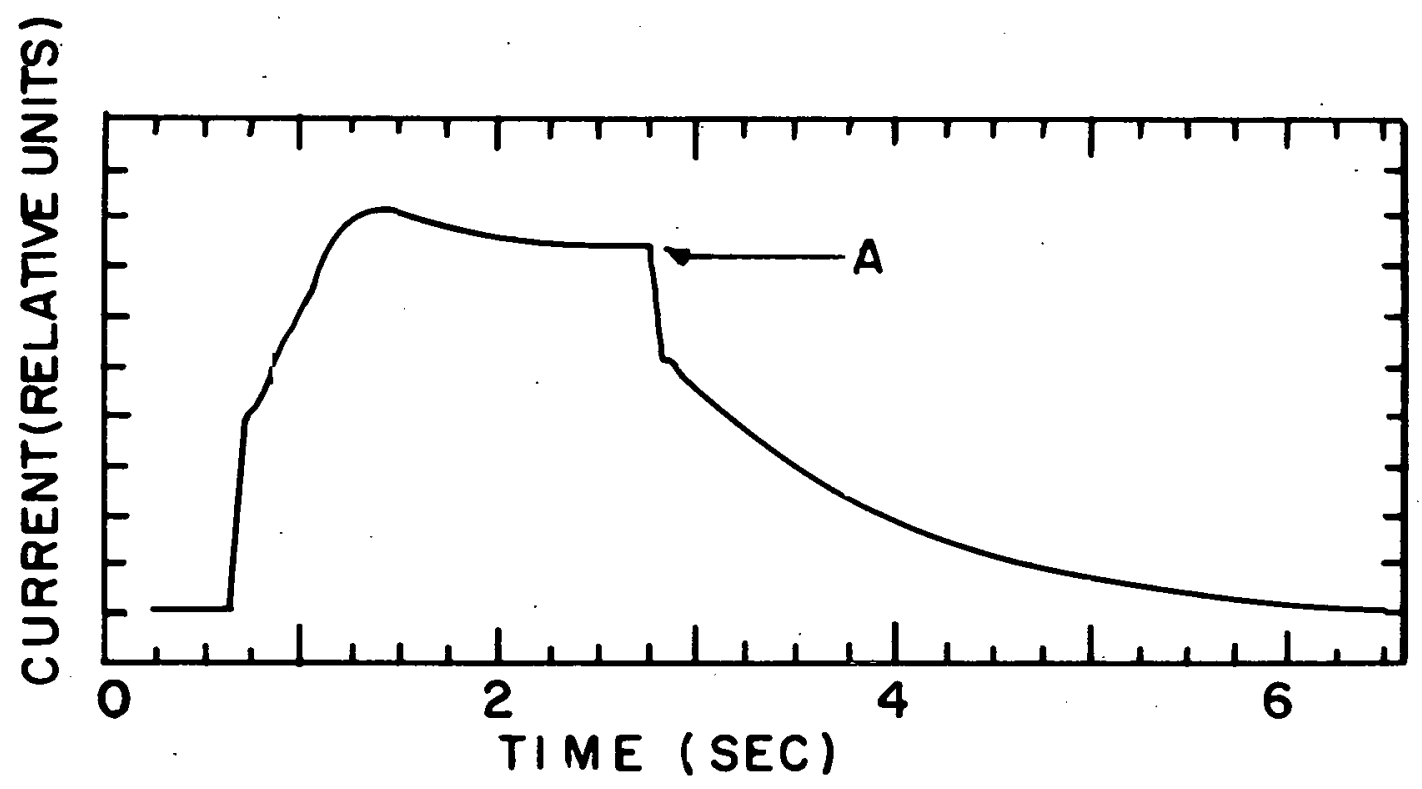

Figure 10.

Non-linear response of spectromagnetic Supply - spectroneter subsyster

$a$ 
III. DESIGN

\section{A. Intuitire Discussion}

Two different designs were proposed. Both were born of intuition. In the original design of the field stabilizer, a. zero steady-state error vas assured and stability could be assured by proper choice of the integration paraineter. The stabilization time was then limited by the integration parameters necessary for stability and by the voltage which the inteqrator must provide to obtain zero steady-state error.

The first design, referred to as system 1 , considered that a better response could be obtained by making as small as possible the integrated roltage necessary to achieve zero steady-state error. Since it is essentially only the nonconstant permeability of the iron in the spectrometer agnet which prevents the field of the spectrometer wagnet from being exactly proportional to the field in the solenoid, a good first try at the new design appeared to be to externally program the spectromagnetic pover supply with a voltage proportional to that wich programs the Alpha scientific power supply. Then the integrator need only supply the voltage necessary to offset the error due to the non-linear permeability effects. This voltage is small compared to that required to program the spectromagnetic supply. 
The signal flow diagram for system 1 is show in figure 11. where $\underline{K}$ is the proportionality constant which, except for non-linear permeability effects, watches the fields of the solenoid and spectrometer magnet. The transfer function for the field of the Alpha scientific supply - Solenoid subsystem is $\underline{\text { Z }} \underline{S}$ and $\underline{\underline{1}} \mathbf{1}$ S is the transfer function for the current in the spectromagnetic supply - spectrometer subsystem. The proportionality constant uich converts the current in the spectrometer coils to magnetic field is EC1. The transfer function 블 represents the non-constant permeability effects. The transfer function of the magnetometer null detector is E06. and $\underline{A} \angle \underline{S}$ is the transfer function for the integrator. The second design. system 2, incorporated the idea that a feedback loop in parallel with the integrator of system 1 should further improve the response of the system. Care had to be taken to maintain stability and to choose the proper gain in the feedback loop so that the response is indeed improved. The signal flow diagram for this system is shown in fiquie 12. The transfer functions are as previously defined with the exception of $\mathrm{KP}$ which is the gain of the parallel feedback.

\section{B. General Response Analysis}

While intuition is sometimes a good starting point for desiqn, a more rigorous foundation is desirable. To provide 


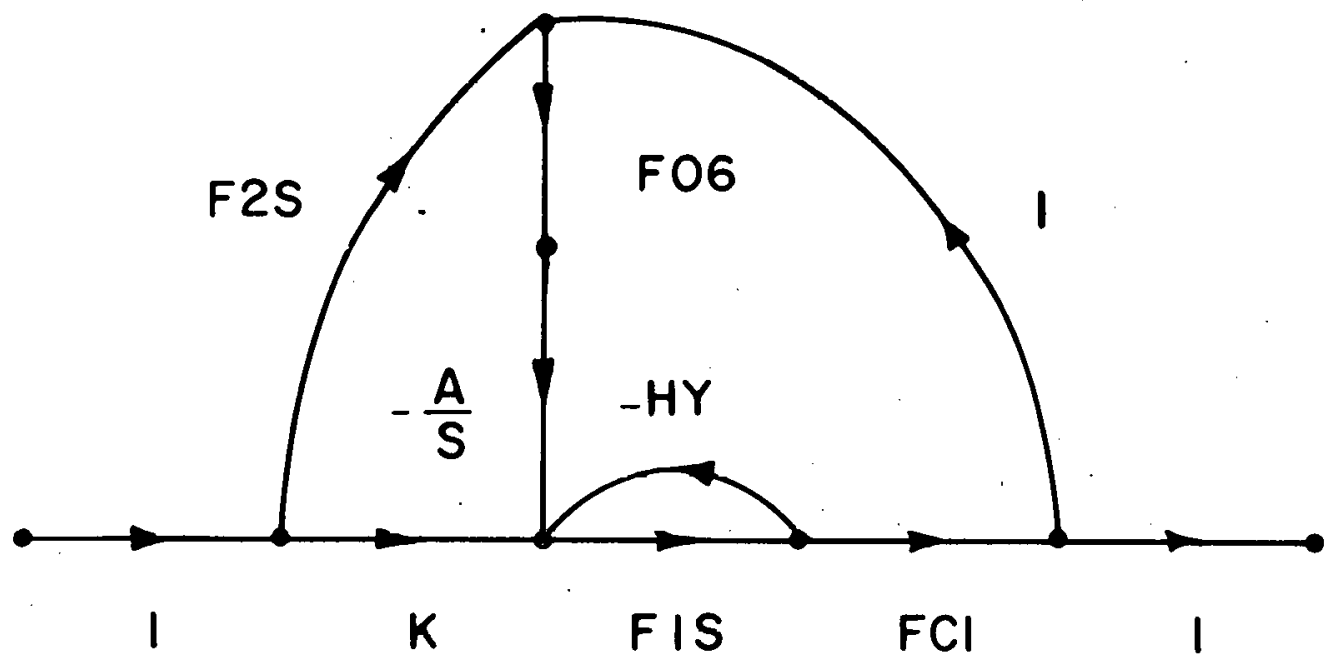

Figure 11. Signal flow diagram of system 1

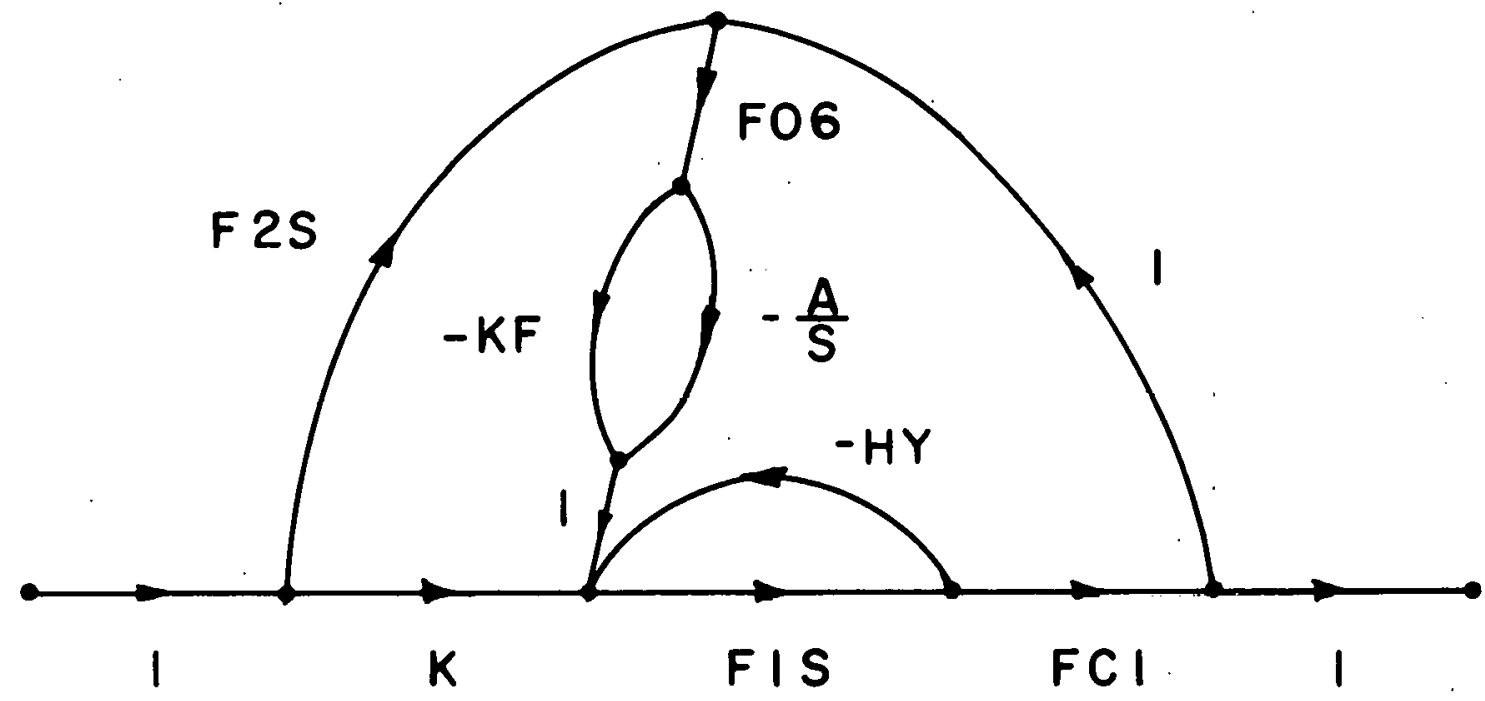

Figure 12. Signal Elow diagram of system 2 
this more rigorous foundation, a Linear systems Analysis pro-

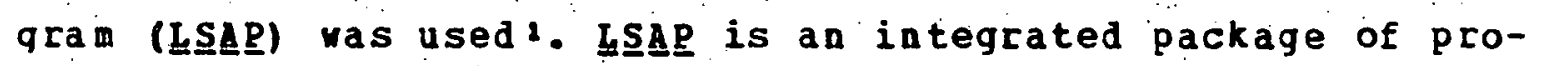
cedures that performs numical computations which are frequently needed in the analysis and design of both continuoustime and discrete-time control systems. The program contains procedures which, among other tasks, will form a transfer function, find its associated frequencl response, determine its response to an input which can be representej by a simple Laplace transform, and provide data for a root-locus plot. One final simplification was made. in the analysis. The analytical function which fits the non-iinearity permeability effects curve was not determined because of the obvious complexity of the analysis involved and because the change in the error voltage over the range of steps taken during actual operation is very small. Instead, values representative of the total range of operation were used to investigate the effect of the magnitude of the error voltage on the poles of the system. The position of the poles ras virtually unchanged as 브 varied between its maximum and minimun values. Again, the prime consideration is that the desired setting time is achieved and that stability is never lost. The root-locus diagram for system 2 is shown in

1 Duven; D. J. Electrical Engineering Department, Iova State University. Ames, Iowa.. Private Commication. 1972. 
figure 13. Roots further out on the negative real axis have been suppressed because they have very little effect on the system performance and for simplicity in presentation. The root-locus diagrams in figure 14 show the effect of adding the parallel feedback, KE, in syste 2. The open circles on the two plots are loci for similar value of A, i.e.. the riqht most open circles on both plots correspond to the same

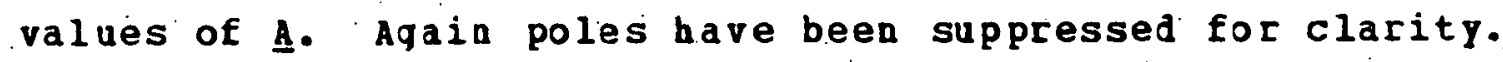
It is readily apparent that the addition of $\underline{R} \underline{F}$ increases the stability of the system for a given value of A. Furthermore, the settling time to within $10 \%$ of the final ralue of a step is shortened. For the value of $\underline{A}=2.0$ the settling times to $10 \%$ are 18.0 seconds and 0.4 seconds for system 1 and 2 respectively. These results support the intuitive ideas.

once the stability of the systems was confirmed, a prototype of the stabilizer was constructed, and the actual values of the parameters $A$ and $\underline{K} \underline{P}$ vere determined experimental1y.: Calculation of these parameters vas not attempted because of the approximations which have been made and because the staircase input for a finite time is difficult to treat analytically.

The analysis leading to the root-locus diagrais gained credibility when a value of $A$ approximately equal to four vas used in the stabilizer prototype with $\underline{\underline{F}}$ equal to zero. The root-locus diagram labelled $K F=0.00$ in figure 14 shows the 


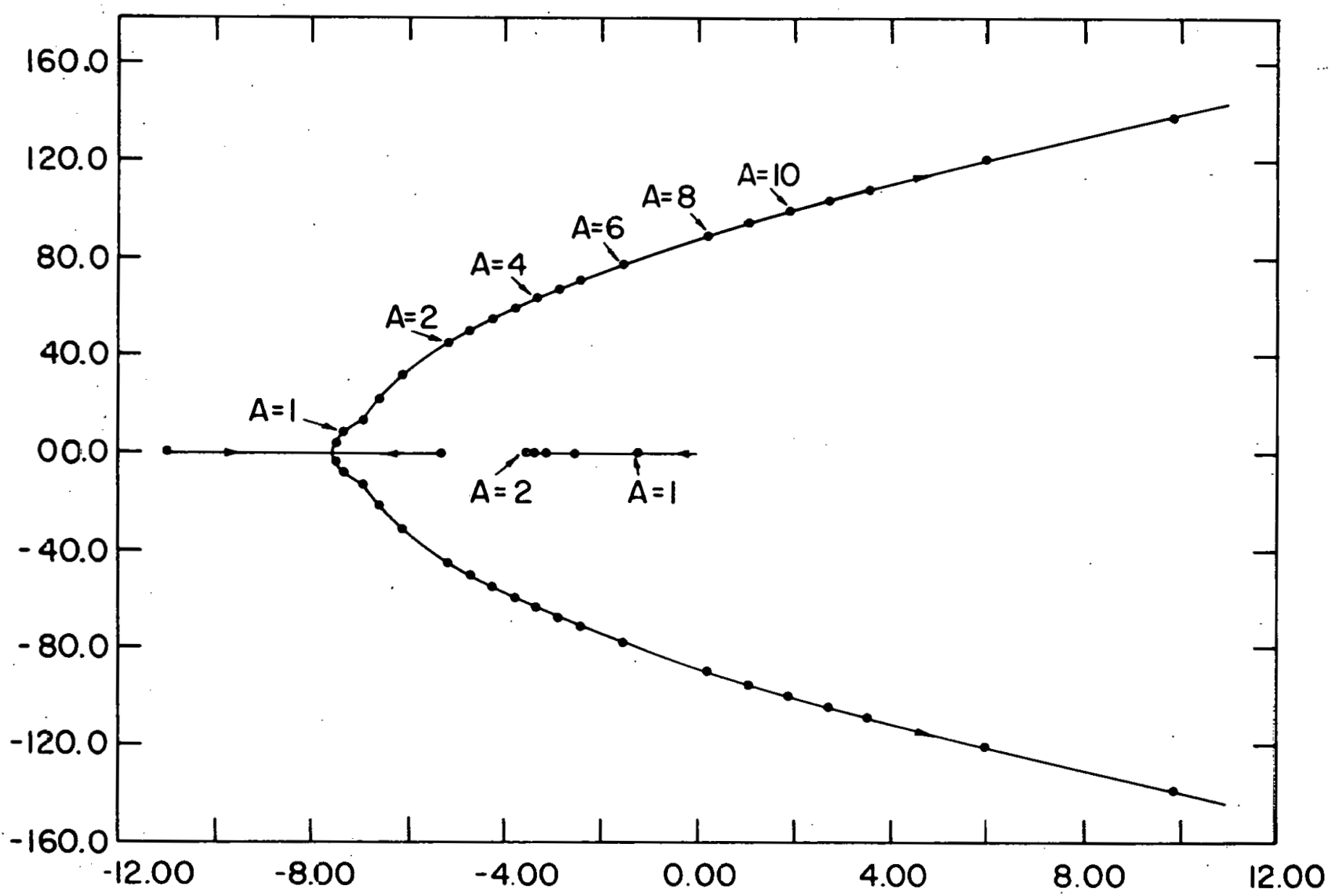

Figure 13. Root-locus diagram of system 2 .

Parameter varied is $A=1 / R C$. 


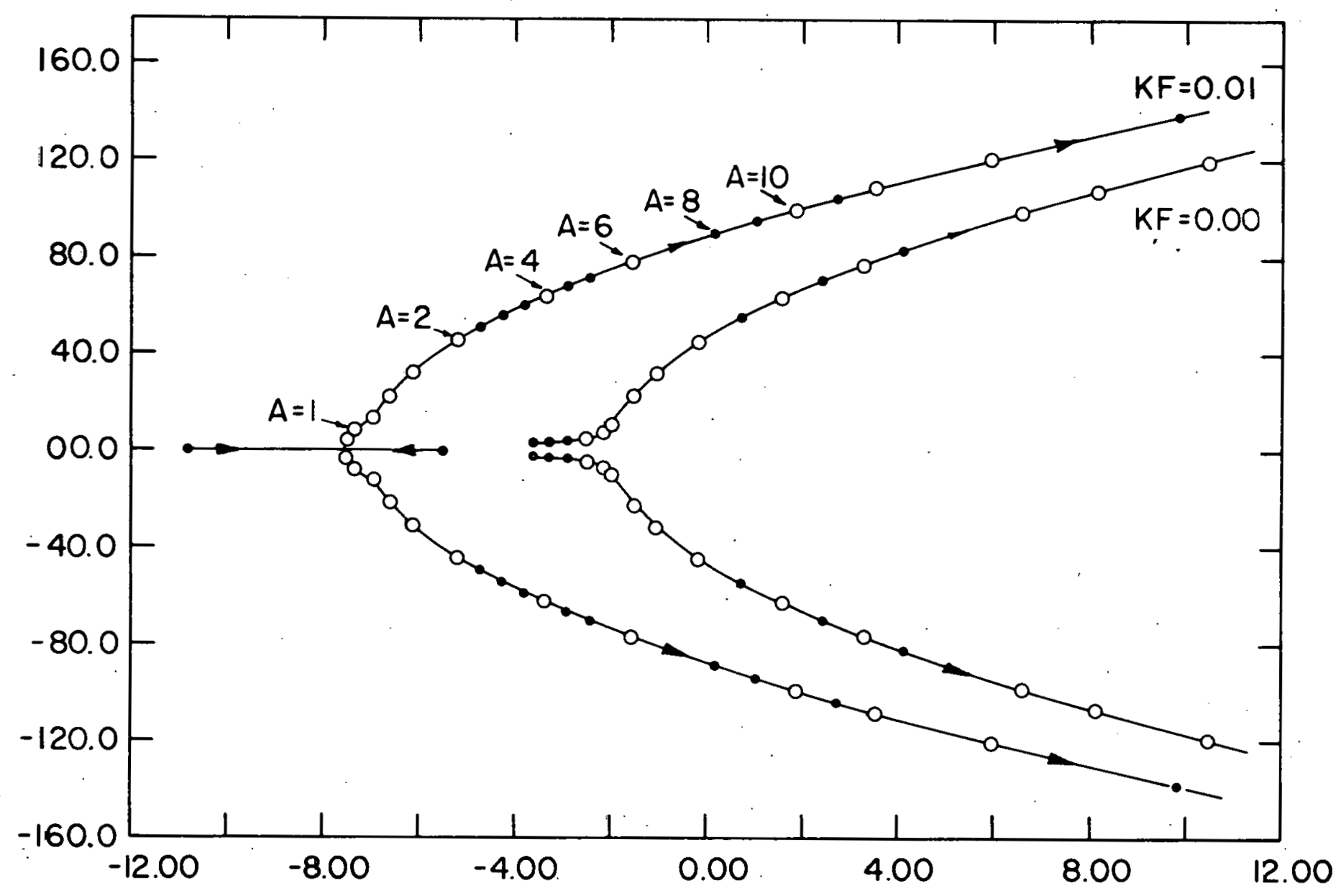

Figure 14. Root-locus diagrams of systems 1 and 2 . Parameter varied is $A=1 / R C$. 
system to be marqinally stable for the value of approximately equal to tro. Considering that approximations have been ade in arriving at the transfer function of the system, this agreement is guite good.

\section{c. Stability}

Once the parameters of the system have been determined, one wust be mindful of the criteria dealing with field reproducibility and stability. To insure stability and reproducibility of the field settings, low-offet and low drift amplifiers and a well regulated power supply, zeltex ZM15200, vere used. All amplifiers used had noise specifications wich vere below 5 microvolts. Input and shunt resistances vere chosen such that noise and offset currents through them vould not produce roltages greater than 50 microvolts. A voltage of 50 microvolts at the input to the spectromagnetic: supply is equivalent to a current change of 10 parts per million of the maximum current. Equal valued, precision resistors vere used in the voltage dividers (Appendix) to insure that heating effects would be held to a miniaụ . 


\section{EVALOATION}

\section{A. System 1}

system 1 with the experimentally determined optimum design parameter $\underline{A}=11$ met the first two design criteria but fell short of the third. The field stability and reproducibility vere checked by repeatedly collecting data over the strong conversion line found in the beta decay of 137cs. The rms deviation of the field wich focuses the leading edge of this conversion line is a measure of the sta: bility and reproducibility of this system, and has been found to be 3.1 milligauss. The maximu deviation from the mean value. observed over a 48-hour period, was 20.2 ailigauss. The system was found to be stable for any size field step. The system ias run from zero field to its maximum value of field and returned to zero. System stability was maintained in both cases.

This system design failed to meet the stabilization time specification. The stabilization times for the original system, system 0 , and systems 1 and 2 are listed in tabie 1. The stabilization times for a.0.23-gauss step at 34.5 gauss and a 11.5-gauss step at 23 gauss vere chosen as being representative of the stabilization times for the respective step sizes over the entire range. The stabilization times vere measured by starting the digital programer to increase the 
field by the desired number of steps and at the same time starting a timer. The timer was stopped as soon as the nonnull field in the solenoid, as indicated on the Herlett packard magnetometer. dropped and remained below 10 milliqauss. The time necessary for the field to be increased by the desired number of steps as subtracted to give the stabilization times. Several readings vere taken for each case and the times were reproducibie to within 0.1 second.

\section{B. System 2}

system 2 with the experimentally determined optimum desiqn parameters $\underline{A}=16.2$ and $\underline{K} \underline{\underline{P}}=0.0016$ wet all of the desiqn criteria. The measurement procedures were the same as those described for system 1. The settling time for a 0.023 -gauss step was less than 0.5 second. For steps larger than approximately 0.085 gauss the stabilization time was

Table 1. Comparison of stabilization times

\begin{tabular}{|c|c|c|}
\hline $\begin{array}{c}\text { System } \\
\text { Identification }\end{array}$ & $\begin{array}{c}\text { Stabilization } \\
0.23-g a u s s \\
\text { step }\end{array}$ & $\begin{array}{c}\text { Times (Seconds) } \\
11.5-g a u s s \\
\text { step }\end{array}$ \\
\hline 0 & 7.8 & 49.2 \\
\hline 1 & 4.6 & 6.0 \\
\hline , & 1.8 & 1.8 \\
\hline
\end{tabular}


constant and equal to 1.8 seconds. The field error for these larger steps does not exceed the value of 20 milligauss during the step. This guarantees that a $180^{\circ}$ change in the phase of the maqnetometer output (mentioned in the introduction) vill not occur.

As vas mentioned previously, one must assure that the control systea will remain stable when the non-linear sleving of the alpha scientific and spectromagnetic supplies occurs. This assurance was provided by the absence of instabilities during testing wich included the worst case condition, specifically, to increase the field from zero to its maximum value, to allow the field to stabilize at the maximan value, and then to decrease the field to zero.

\section{Unpredicted Instability}

An observation vas made wich is apparently a contradiction to the root-locus diagrams.' It vas observed that as $\underline{\text { R }}$ was increased system 2 became unstable. The rootlocus diaqrams in figure 14 indicate that as $\underline{K} \underline{F}$ is increased. the stability of the spstem is increased. This paradox may be resolved by attributing the unexpected behavior to a transportation lag in the spectromagnetic pover supply. Such a transportation lag rould introduce a multiplicative term, $e^{-T S}$. where $T$ is the transportation lag in the spectromagnetic supply - spectrometer transfer function. 
Analysis of such a systen could be done by expaning $e^{-T S}$ as a series; however, an acceptable design has been found without this extensive analysis; and it is sufficient to state that a transportation lag has been observed in the spectromagnetic power supply and that such transportation laqs have been known to cause instabilities in similar systems wen the parailel feedback becomes too great:

ISkank, Harold. Instrumentation Group, Ames Laboratory. USAEC, Ames. Ióva. Private Communication. 1972 . 


\section{LITERATURE CITED}

1. Eitter, Joseph J., and W. L. Talbert; Jr... "The Construction and Alignment of a High-resolution Beta-ray spectrometer". AEC Report ro. IS-1950, August 1968.

2. Sieqbahn, K., Alpha-, Beta-, and Gama-Ray Spectroscopy. North Holland Publishing Company. Amsterdam, 1955.

3. Bartlett, A. A. and Shafer, Keith, Measurement and Control of the Magnetic Field in a Beta spectrometer"; The Review of Scientific Instruments, Vol. 35, No. 8, August, 1964. p 1072 .

4. Dionisio, J. S. and Guterman, C., "Application de la methode des transformateurs satures a la mesure et regulation du champ magnetique dun spectrometre beta a double focalisation $\pi \sqrt{2}$ arec noyau de fer". Nuclear Instruments and Hethods, Vol. 67, No. 2, 1969, p 213.

5. Hulphrey, 1: "A: "Aeneral minimizing routine-Mrifun", Programer's Notes P-6,9.7.62; UCBL Berkeley, october 1964. 
VI. ACKNOHLEDGEGENTS

The assistance of several people made the completion of this thesis a pleasant job. I yould like to thank Dr. Terry Smay, who served as my thesis advisor and who handied the paper work enabling me to get this degree in Engineering while pursueing wy $P$ h. D. work in the Physics Departaent.

The field control unit was built for use with the betaray spectrometer of the TRISTAN facility of the Ames Laboratory Research Reactor. I vould like to thank the Ames laboratory for the opportunity to perform this work, and Dr. Willard L. Talbert, Jr., who has been responsible for the development and continued existence of the TRISTAN group.

Dr. Pred $K$. Hohn, my immediate supervisor for my Ph.D. work, deserves a special thanks for the guidance he has given me in my work with the beta-ray spectrometer which included helpful aiscussions on the requirements of the field control system.

Finally to wy we Marilyn, who has labored very diliqently oper the typing of this thesis, I vould like to express wy deep appreciation for her support during y degree work. 
VII. APPENDIX: CIBCUIT DIAGRAM

A simplified schematic of the control circuitry is shown in fiqure 1. The error voltage input comes frox the Hewlett-Packard magnetometer. The programing voltage input is supplied from the pluke voltage calibrator which has a maximum output of 50 volts. The Alpha scientific power supply requires 20 volts input for maximum current. One tap of the voltage divider provides the correct proportion of the programing voltage to the Alpha scientific supply. The other tap supplies tuice the proper proportion of the programing voltage to the summing amplifier $B, e . g ., 10$ volts for a Fluke output voltage of 50 volts. The additional factor of two attenuation is provided by the suming amplifier $B$.

The error voltage is integrated with a time constant $\tau=$ BC where $C$ is fired at 90 microfarads. The design parameter 1 referred to in the text of the thesis is related to the circuit colponent values by the equation

$$
A=\frac{0.5}{R C}
$$

The factor 0.5 comes from the attenuation of the signals applied to the non-inventing inputs of amplifier B. The error voltage is also reduced by the catio 


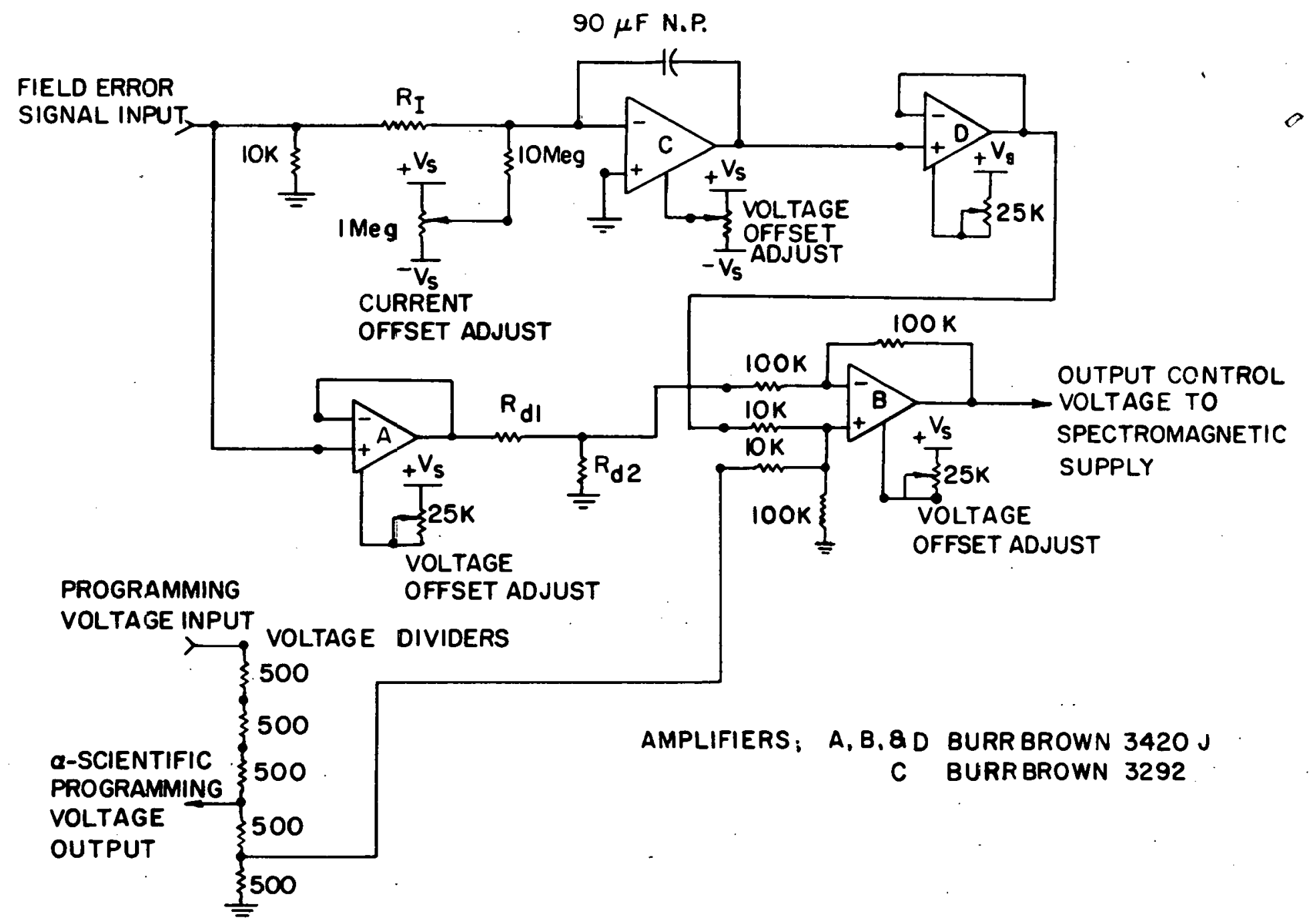

Fiqure A1. Schematic diagram of field stabilizer 


$$
K F=\frac{R_{d 2}}{R_{d 1}+R_{d 2}}
$$

and summed by amplifier B. The ratio $\underline{\text { KE}}$ is the design parameter associated with the parallel feedback. The output of amplifier $B$ provides the input to the spectromagnetic power supply. It should be noted that in the actual control circuit and $\underline{\text { X }}$ are effectively a factor of ten larger due to the magnetometer gain used during normal operation. Anplifier $D$ serves as a high-impedance buffer for the integrator. This allows the control circuit to be used in an operate-hold type systen in which the error voltage is removed from the input to the integrator and the integrated error voltage remains constant, when the system is switched from the operate mode to the hold mode. 